\title{
AVALIAÇÃO AMBIENTAL EM UM REFEITÓRIO DE RESIDENCIAL GERIÁTRICO SOB A ÓTICA DA PERCEPÇÃO AMBIENTAL E DA ERGONOMIA
}

\author{
BINS ELY, Vera Helena Moro (1); \\ SCHMITT KERCHNER, Isabela Guesser (2); \\ SOUZA, Juliana Castro (3)
}

(1) Universidade Federal de Santa Catarina, Doutora em Engenharia de Produção.

e-mail: vera.binsely@gmail.com

(2) Universidade Federal de Santa Catarina, Mestranda em Arquitetura e Urbanismo.

e-mail: isagschmitt@gmail.com

(3) Universidade Federal de Santa Catarina, Doutoranda em Arquitetura e Urbanismo.

e-mail: juliana@ja8.com.br

\begin{abstract}
RESUMO
Este estudo consiste em uma análise do ambiente de um refeitório em uma casa de repouso para pessoas idosas, cuja maioria possui doenças degenerativas como Mal de Alzheimer. A pesquisa de caráter qualitativo foi realizada sob a ótica da ergonomia e da psicologia ambiental utilizando métodos de observação e entrevista, a fim de investigar como o ambiente se apresenta para os funcionários diretamente envolvidos no momento da alimentação dos pacientes. Os resultados retratam aspectos relativos à dinâmica cotidiana de execução das atividades, bem como a influência de característica do ambiente nas mesmas. A partir desta análise foram elencadas recomendações de ordem arquitetônica para melhorias no espaço analisado.
\end{abstract}

Palavras chave: Alimentação, Idosos, Avaliação Ambiental.

\begin{abstract}
This study consists in an environment analysis of a nursing home dinning room for the elderly, where most residents suffer from Alzheimer's disease. Qualitative research was carried out from the perspective of ergonomics and environmental psychology using methods of observation and interview, in order to investigate how the environment presents itself to the employees directly involved in the moment of feeding the patients. The results portray aspects related to the daily activity execution dynamics as well as the influence of the characteristics of the environment in them. From this analysis architectural recommendations for improvements in the analyzed space were listed.
\end{abstract}

Keywords: Food, Elderly, Environmental Assessment.

\section{INTRODUÇÃO}

Este estudo consiste na análise de um refeitório em um residencial geriátrico no qual a maior parte dos residentes possui doenças degenerativas como o Mal de Alzheimer, Doença 


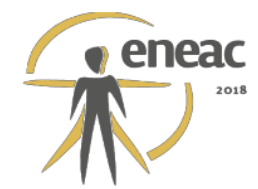

de Parkinson e/ou outros distúrbios que afetam tanto a independência quanto a autonomia dos idosos.

Garcia de Menezes et al (2010) colocam que a alimentação corresponde à noção ampla e potencialmente capaz de abarcar componentes de felicidade, de bem-estar e de segurança, no cotidiano de pessoas de todas as idades. A alimentação é fundamental para a saúde do idoso, não apenas para sua saúde física mas para sua saúde integral, incluindo aspectos sociais e psicológicos. A alimentação é um dos poucos prazeres que os idosos com limitações físicas e mentais possuem.

Existem vários fatores que podem dificultar a alimentação dos idosos quando se trata do estado de saúde de cada indivíduo. Com as doenças degenerativas há perda gradual de habilidades e aptidões necessárias para alimentar-se, levando a necessidades especiais, como consistência específica para a comida, instrumentos adequados, auxílio de terceiros e outros. São várias limitações físicas como, por exemplo, a dificuldade de deglutição e a perda gradual de coordenação motora dos idosos, que tornam a alimentação uma atividade complexa em um residencial geriátrico. O espaço físico onde ocorre esta atividade pode dificultar ou facilitá-la, em função de suas características ergonômicas, estruturais e de conforto ambiental.

A relação entre o ambiente e a alimentação foi estudada com foco nos residentes: pessoas idosas, bem como nos funcionários, já que estes estão diretamente envolvidos nessa atividade. Buscou-se identificar quais aspectos de humanização e elementos estruturadores do espaço favorecem ou dificultam a alimentação dos idosos e quais os traços de comportamento e de apropriação destes usuários no ambiente.

\section{OBJETO DE ESTUDO}

O residencial geriátrico situa-se próximo a um centro urbano, mas o terreno onde está inserido é rodeado de vegetação e inclui jardins arborizados. O ambiente avaliado foi o refeitório, localizado no pavimento térreo da edificação, com área total de $29 \mathrm{~m}^{2}$ e com vista direta para o jardim (Figuras 1,2 e 3). É importante destacar que a edificação não foi originalmente concebida para ser um residencial geriátrico, mas adaptada posteriormente para comportar este uso.

Figura 1 - Vista Externa do Residencial.

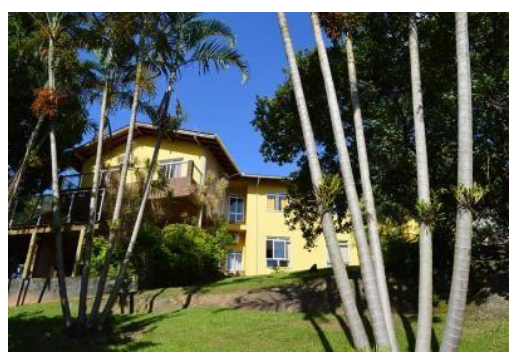

Fonte: Site da Instituição.
Figura 2 - Vista do Deck.

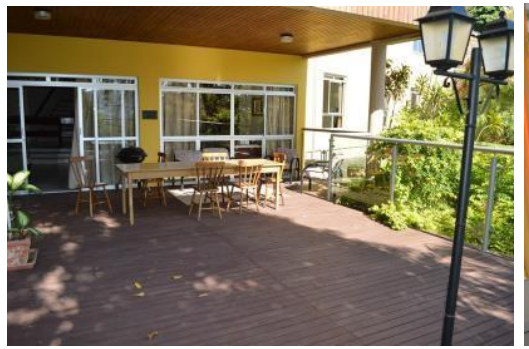

Fonte: Site da Instituição.
Figura 3 - Vista Refeitório.

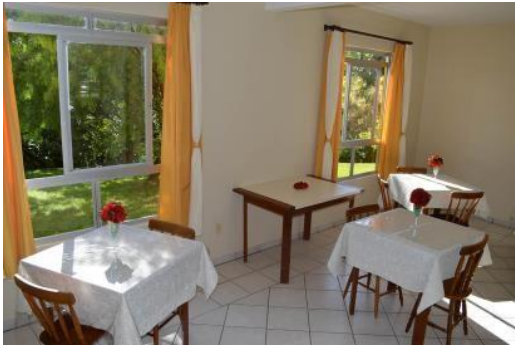

Fonte: Site da Instituição.

O refeitório faz parte de um conjunto de ambientes componentes da área de convívio, a qual ainda inclui sala de convivência, deck externo, capela e jardim arborizado. As relações espaciais diretas com o refeitório ocorrem na copa e no corredor de circulação.

O ambiente dispõe de mesas com quatro lugares, estantes e um buffet em inox com nove compartimentos. Outros objetos de decoração complementam o espaço, como quadros e vasos de flores. Cores claras e objetos decorativos transmitem sensação agradável (Figuras 


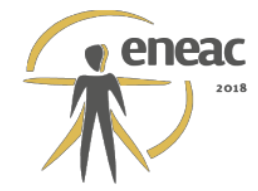

4 e 5). Destaca-se a iluminação e ventilação natural, provenientes de duas janelas voltadas para o jardim arborizado.

O layout atual sugere a centralização da zona de preparo dos pratos (mesa e buffet em inox). $\mathrm{Na}$ parede oposta às janelas há estantes que apoiam o preparo dos pratos e 0 descarte dos resíduos e utensílios já utilizados nas refeições. Nas laterais em direção às janelas estão quatro mesas com 4 cadeiras cada (Figura 6).

Figura 4 - Vista Interna

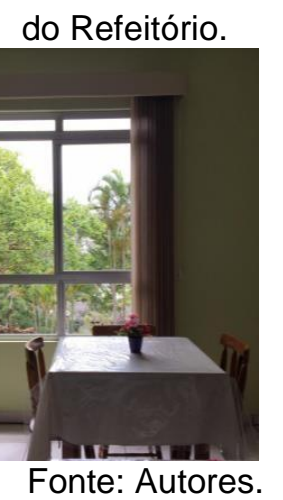

Figura 5 - Vista Interna do Refeitório.

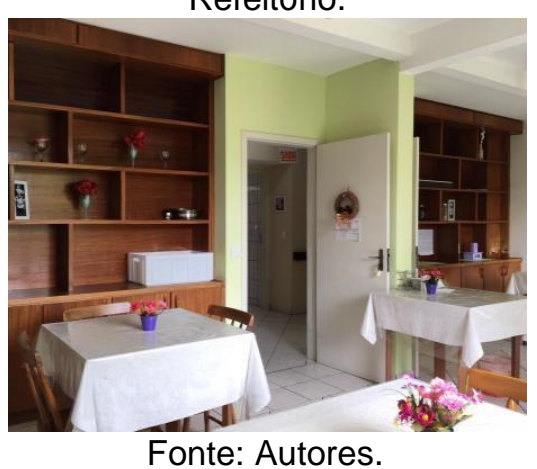

Figura 6 - Leiaute do

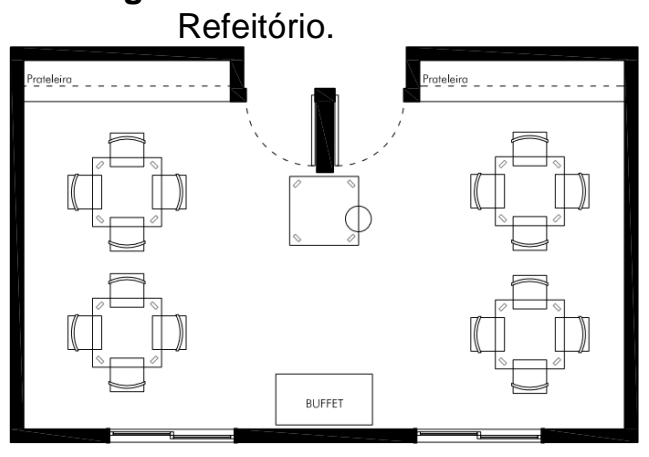

Fonte: Autores.

O residencial comporta atualmente 17 residentes, tendo capacidade máxima de 19 . Ao todo possui 27 funcionários. A maior parte destes exerce suas atividades em regime de 12 horas de trabalho e 36 horas de descanso, sendo o caso dos técnicos em enfermagem e dos cozinheiros. Estão envolvidos diretamente na atividade de alimentação os seguintes profissionais: cozinheiro e auxiliar de cozinha, técnicos em enfermagem, cuidador, enfermeiro chefe, fonoaudiólogo, nutricionista e faxineiro.

Dos funcionários envolvidos na alimentação dos idosos a cozinheira e a auxiliar de cozinha são responsáveis pela organização do refeitório no pré-preparo, no preparo e na finalização dos alimentos, conforme cardápio elaborado pela nutricionista e orientações da fonoaudióloga. Os técnicos em enfermagem, cuidadora e enfermeiro chefe são os responsáveis diretos no momento da alimentação, que inclui desde a locomoção até o refeitório, o ato de servir e alimentar os residentes. Existem particularidades nesta atividade em função da condição de cada residente. Alguns se alimentam com autonomia, outros necessitam que os alimentos sejam levados à boca por terceiros. Há ainda os que utilizam sonda nasogástrica e recebem dieta pastosa, sendo que estes últimos não frequentam o refeitório.

Nem todas as refeições são realizadas no refeitório. De modo direto 8 dos 17 residentes utilizam o espaço durante o almoço, café da tarde e jantar. $O$ café da manhã é servido nos quartos para conciliar o tempo entre as necessidades matinais de cada residente e a dinâmica de realização das atividades por parte dos funcionários neste período. Quando acordam muitos precisam ser higienizados porque utilizam fraldas. Outros praticam sessões de fisioterapia ainda na cama. Por estes motivos convencionou-se servir o café individualmente nos quartos.

\section{MÉTODOS E TÉCNICAS}

A estratégia metodológica aplicada neste estudo parte de princípios da abordagem qualitativa de pesquisa. Minayo (2011) divide o processo de trabalho científico de pesquisa qualitativa em três etapas: fase exploratória com o trabalho de campo, análise e tratamento 


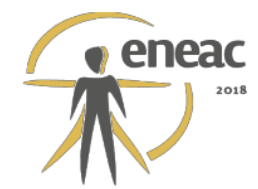

do material empírico e documental.

Com base neste processo, foi realizada em um primeiro momento, a observação assistemática, que possibilitou um conhecimento aprofundado das dinâmicas existentes no ambiente estudado. A partir daí foi traçada uma estratégia multimétodos, a fim de operacionalizar os objetivos específicos do estudo, de acordo com a tabela 1 a seguir.

Tabela 1 - Estratégia Metodológica.

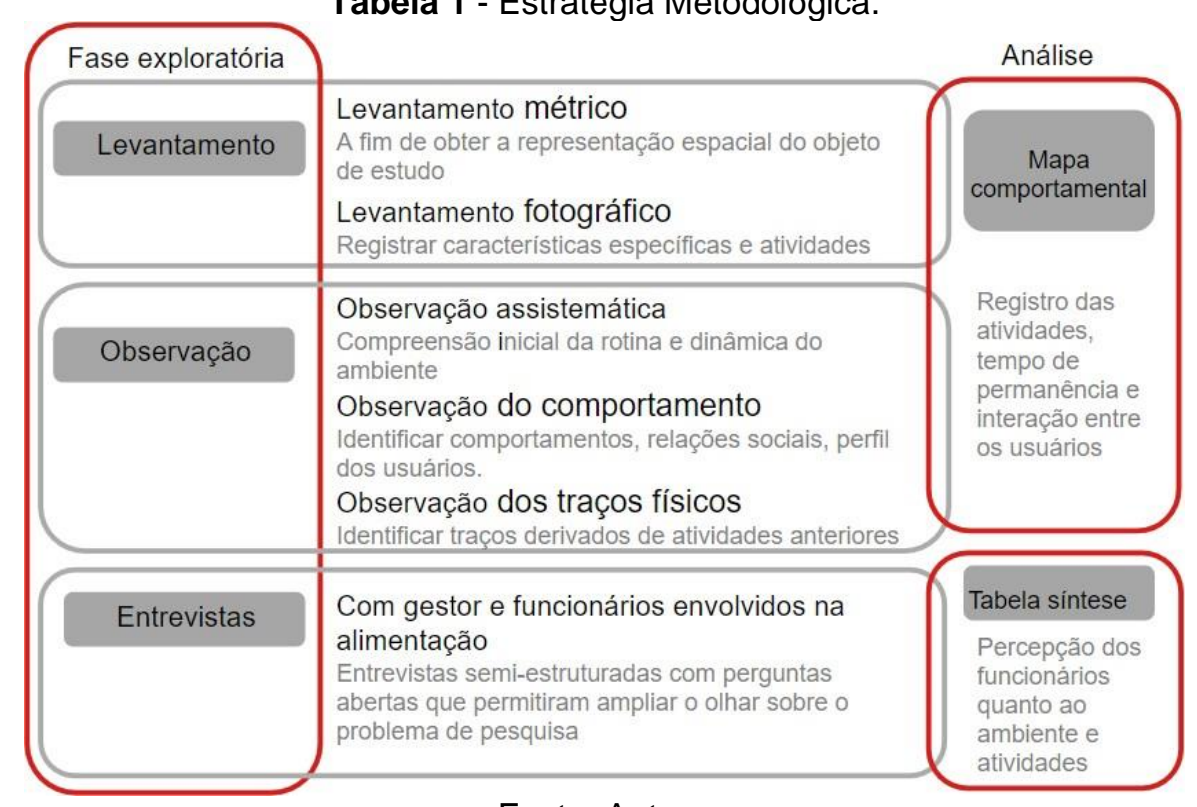

Fonte: Autores.

Os métodos aplicados durante a fase exploratória resultaram em mapas comportamentais e tabelas síntese que combinam os resultados das observações e entrevistas.

Para efetuar os levantamentos foram realizadas visitas ao local, cada qual com objetivos específicos. Na primeira delas, foi possível obter um panorama geral da rotina e funcionamento do residencial geriátrico nas áreas de convivência, assim como a escolha do objeto de estudo. Também foi feita uma entrevista aberta com a gestora e proprietária do residencial geriátrico, a fim de compreender aspectos relacionados à dinâmica geral do lugar. $\mathrm{Na}$ segunda visita foram realizados os levantamentos métrico e fotográfico do refeitório.

As observações tiveram como objetivo verificar como as atividades ocorrem e quais as oportunidades e limitações que 0 ambiente oferece. Neste estudo foram apoiadas teoricamente pela aplicação do método de observação do comportamento, desenvolvido por Zeisel (1995), que visa compreender a interação entre os usuários e o espaço físico. E também pelo método de observação dos traços físicos (Zeisel, 2006), onde foram procurados vestígios das atividades no ambiente físico, que podem ser produzidos de forma consciente ou inconsciente.

As visitas destinadas às observações do comportamento e traços físicos ocorreram por cerca de 1 hora durante o almoço (às 12h) e o café da tarde (às 15h), em dias distintos. Após as observações, nos mesmos dias foram realizadas entrevistas semi-estruturadas com os funcionários envolvidos na alimentação dos residentes.

Com o grupo de funcionários que atuam diretamente no refeitório, a entrevista buscou informações em três categorias: características pessoais, atividades desempenhadas e relação com ambiente de trabalho. Os residentes (idosos) não foram entrevistados, porque a equipe gestora julgou não ser adequado, considerando que apresentam especificidades 


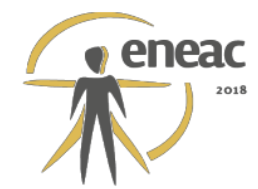

cognitivas decorrentes de sua condição de saúde que dificultam a formação de ideias claras.

\section{RESULTADOS}

Durante as visitas exploratórias, com aplicação dos distintos métodos propostos puderam ser observados conflitos no desenvolvimento das atividades decorrentes do espaço físico do refeitório. As causas destes conflitos estão relacionadas com o leiaute, mobiliário e dimensões do espaço.

Quanto ao leiaute observou-se que apresenta conflitos de fluxo. Na entrada do refeitório há cruzamento entre os funcionários que circulam para abastecer o buffet e aqueles que atuam no preparo e distribuição dos pratos. O mesmo ocorre nos fluxos em direção às estantes, devido à descentralização da bancada de apoio para preparação e recolhimento dos pratos.

Apesar do conflito de fluxos observados na entrada do ambiente, a proximidade da cozinha e do refeitório com o corredor de acesso ao elevador foi citada nas entrevistas como um aspecto positivo. Essa proximidade permite aos residentes ver a movimentação de preparo das refeições, ouvindo os sons da cozinha, sentindo o cheiro da comida e vendo o ambiente do refeitório ser organizado para o momento da refeição. A fonoaudióloga entrevistada afirmou que os estímulos sensoriais são extremamente importantes para manter viva a vontade de comer no idoso e que, comparado com outros residenciais onde trabalha, nos quais a comida vem pronta e é fornecida por uma empresa terceirizada, o apetite dos idosos é menor.

Também foi avaliado o arranjo espacial do mobiliário e verificou-se que a distância entre as mesas não atende as dimensões mínimas de circulação, de acordo com Panero \& Zelnik (2014). O que ocorre na prática é que as quatro mesas são utilizadas, mas sobram cadeiras. Isso acontece porque as mesas são pequenas e quando ocupadas por um cadeirante não é possível que outras três pessoas sentem. Falta espaço para acomodar as pernas.

O mapa a seguir apresenta o mobiliário utilizado, as atividades desempenhadas, e também cruzamento dos fluxos para realização das mesmas. Durante o café da tarde são utilizadas duas bancadas de apoio para preparação dos alimentos (Figura 7), indicadas com os números 01 e 02, referentes à mesa central e à estante. Já durante o almoço (Figura 8) são utilizadas a mesa central e o buffet, também indicadas com os números 01 e 02 . Indicados com o número 03 estão as mesas para refeição, onde os residentes recebem a comida já organizada em pratos individuais pelos funcionários. Estes explicam o cardápio e perguntam para cada um dos idosos o que desejam comer. $\mathrm{O}$ item 04 representa o local onde são guardados os pratos e utensílios utilizados, que serão encaminhados para a copa.

Figura 7 - Mapa Comportamental - Fluxos, Café da Tarde $15 \mathrm{~h}$.

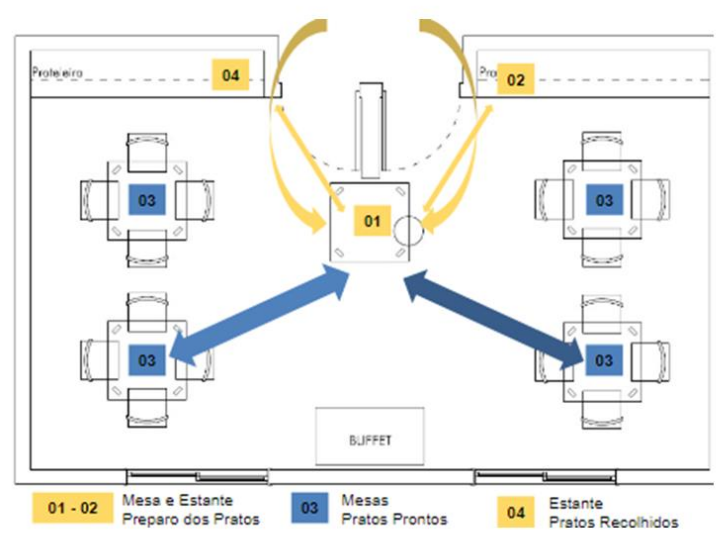

Fonte: Autores.
Figura 8 - Mapa Comportamental - Fluxos, Almoço $12 \mathrm{~h}$.

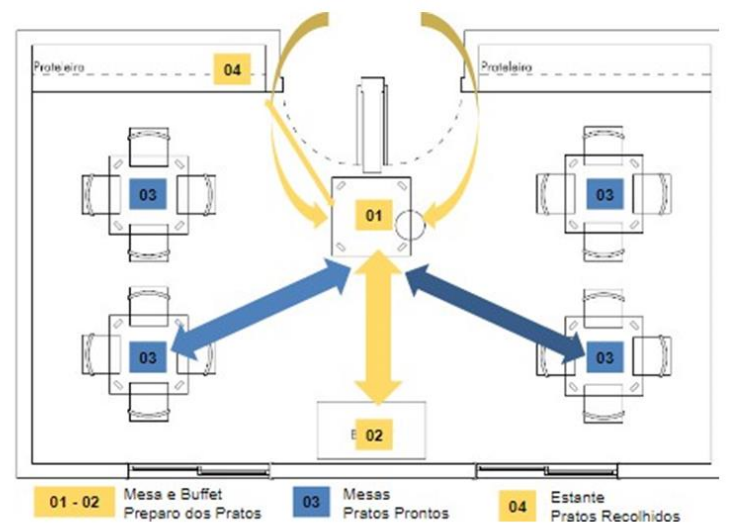

Fonte: Autores. 


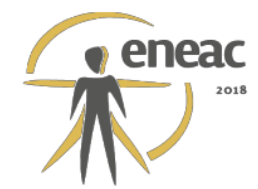

O mobiliário apresenta características conflitantes, identificadas tanto nas observações quanto nas entrevistas. Por meio de uma análise antropométrica foi possível verificar as condições ergonômicas dos equipamentos e do mobiliário do refeitório, em relação ao perfil dos funcionários. Foram realizadas simulações com manequins nos percentis femininos $5 \mathrm{e}$ 95, escolhidos devido à rotatividade de funcionárias do sexo feminino.

Foram simuladas as posturas adotadas pelos funcionários envolvidos nas seguintes tarefas: 1) preparo dos pratos na mesa central e no buffet em inox; 2) e alimentar os residentes que necessitam da ajuda.

$\mathrm{Na}$ simulação de uso da mesa central (Figuras 9 e 10) verificou-se que o manequim de maior estatura necessita inclinar-se para executar a tarefa, demonstrando que a altura do mobiliário não atende as dimensões de altura mínima para realização dessa atividade. Isso ocorre porque uma mesa comum, com dimensões inadequadas, foi adaptada para o uso de bancada de apoio para a montagem dos pratos.

Figura 9 - Simulação Percentil 5 - Preparo dos Pratos.

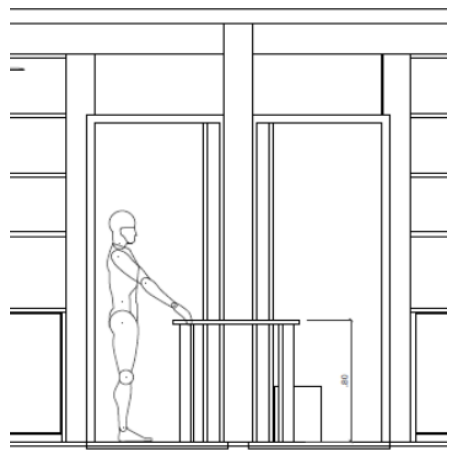

Fonte: Autores.
Figura 10 - Simulação Percentil 95 - Preparo dos Pratos.

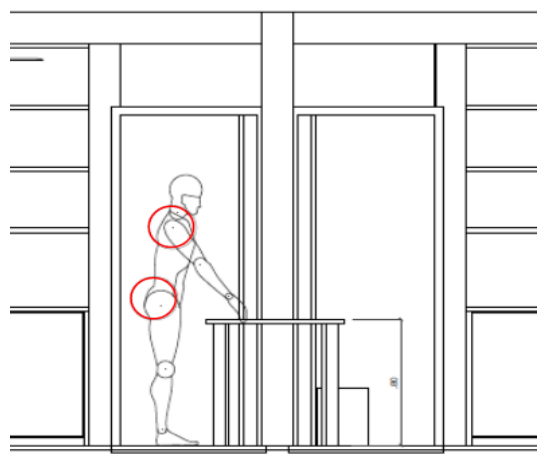

Fonte: Autores.

A simulação abaixo apresenta o uso do buffet em inox. Observa-se que o manequim de menor estatura (Figura 11) apresenta dificuldades em visualizar os pratos expostos na prateleira de cima. Já o manequim de maior estatura (Figura 12) tem um maior campo de visão e consegue utilizar o buffet com mais facilidade.

Figura 11 - Simulação Percentil 5 - Preparo dos Pratos - Buffet.

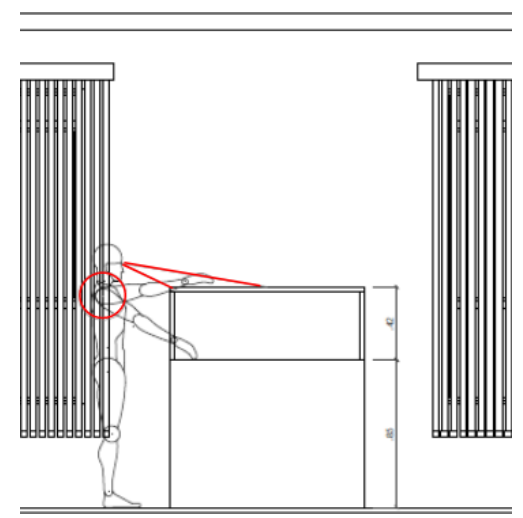

Fonte: Autores.
Figura 12 - Simulação Percentil 95 - Preparo dos Pratos - Buffet.

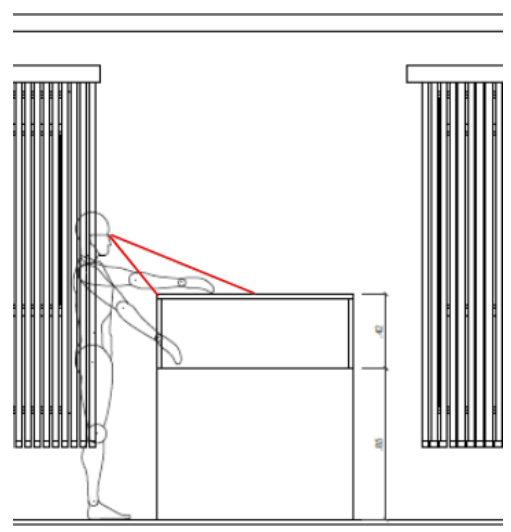

Fonte: Autores.

Por fim, na simulação em que um funcionário auxilia um idoso a alimentar-se, levando a 


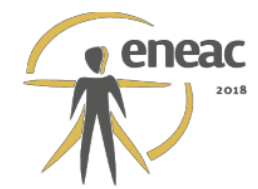

comida até a boca, verificou-se que o mobiliário não permite a aproximação do funcionário até o prato. Nos dois percentis (Figuras 13 e 14) nota-se que o manequim precisa inclinar-se em direção à mesa para conseguir servir o residente. Somado a falta de espaço físico o mobiliário impede a realização da tarefa com conforto. $O$ fato do funcionário não conseguir aproximar-se adequadamente soma-se a outro problema: o design das mesas. A largura livre entre os apoios da mesa não permite a aproximação integral de uma pessoa em cadeira de rodas, tanto pelo observado na prática quanto comparado com os padrões sugeridos na NBR 9050 (2015).

Figura 13 - Simulação Percentil 5 - Servir a Refeição.

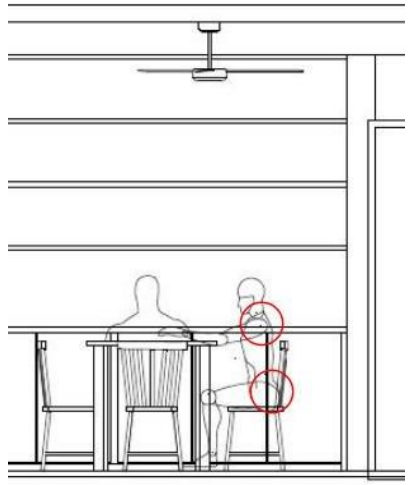

Fonte: Autores.
Figura 14 - Simulação Percentil 95 - Servir a Refeição.

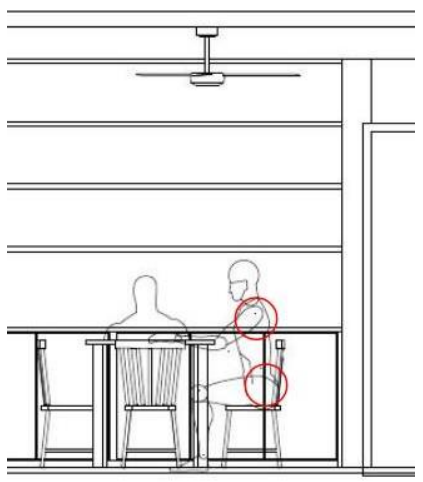

Fonte: Autores.

As entrevistas confirmam que o dimensionamento do mobiliário atrapalha a execução das atividades. Os funcionários citaram a dificuldade para acomodar os usuários de cadeiras de rodas nas mesas em função de seu design e dimensões (Figuras 15 e 16).

Os funcionários entrevistados colocaram que falta espaço para montar os pratos e servir os alimentos. Uma solução seria aumentar a mesa de apoio que está centralizada no ambiente. Os entrevistados também mencionaram que os armários laterais cumprem a função de complementar a bancada de trabalho, apoiando bandejas, pratos, sanduicheira e outros utensílios, porém sobra muito espaço, são subutilizados e estão mal posicionados. Estas estantes tiveram seu uso adaptado para o refeitório, enquadrando-se na classificação de adaptações de uso por Zeisel.

Figura 15 - Conflitos referentes ao Leiaute Circulações.

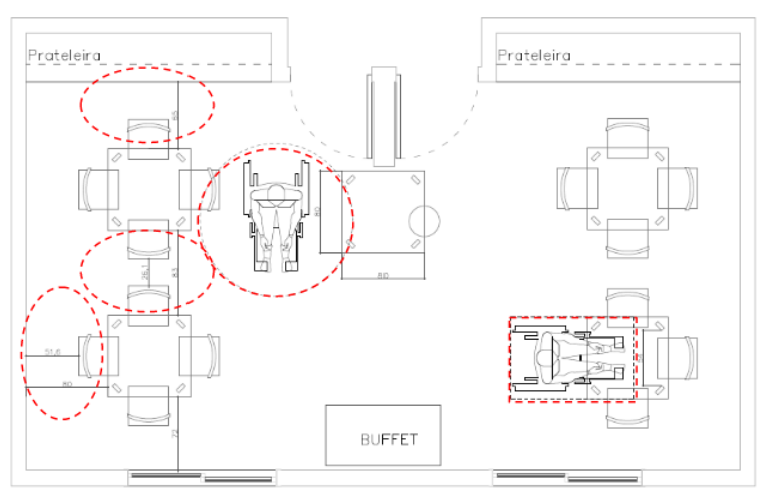

Fonte: Autores.
Figura 16 - Fluxos e Descentralização das Bancadas de Apoio.

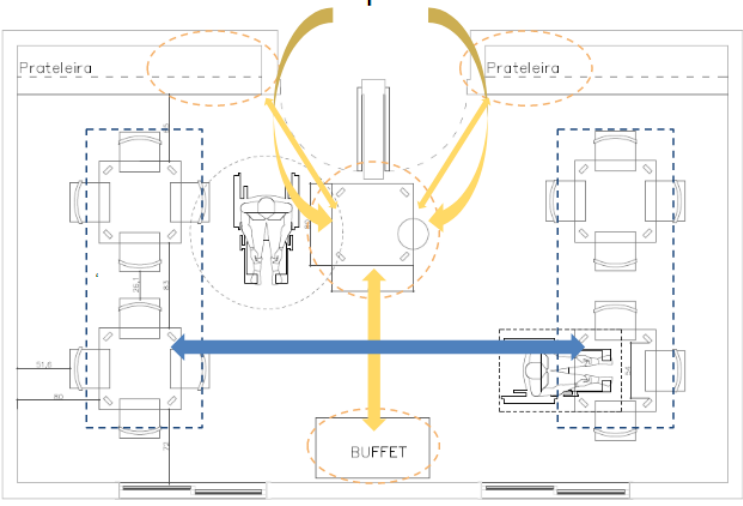

Fonte: Autores. 


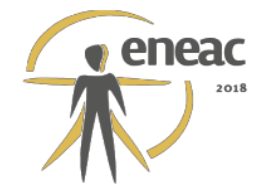

$\mathrm{Na}$ categoria de produtos do uso (Zeisel, 2006) foram observados desgaste das paredes com marcas das cadeiras e do buffet em inox. Isso demonstra que o mobiliário é arrastado para adaptação do leiaute existente às atividades que ocorrem no espaço.

Nas entrevistas as dimensões do refeitório e o mobiliário são os itens mais citados. Segundo os funcionários há falta de espaço para acomodar todos os residentes porque muitos utilizam cadeiras de rodas.

Além das características do espaço físico, a análise ambiental incluiu a observação de aspectos sociais, como a interação entre os usuários no espaço. Foi identificado que existe pouca interação entre os idosos nas mesas, com exceção das interações com visitantes, em geral familiares que estavam presentes na hora das refeições.

É interessante destacar que foi observado que cada residente já tem o seu lugar na mesa, indicando uma apropriação do espaço com traços de territorialidade (Gifford, 1987). Os funcionários confirmaram nas entrevistas que os idosos costumam sentar-se sempre nos mesmos lugares no refeitório e que interagem pouco entre si.

Como distração positiva no ambiente (Ulrich, 1995) verificou-se que o visual das janelas para o jardim arborizado é o principal estímulo. Os entrevistados destacaram a relação do ambiente com o exterior. Porém durante o verão, no período da tarde, as cortinas são fechadas devido à insolação direta, perdendo assim esse contato com os elementos naturais do exterior, que promovem estímulos que distraem positivamente os idosos.

O conforto ambiental foi o aspecto mais positivo do ambiente analisado, do ponto de vista dos entrevistados. O ambiente é entendido pelos funcionários como um lugar calmo, silencioso, ensolarado e bem ventilado. O prazer de trabalhar em um lugar rodeado pela natureza foi mencionado várias vezes.

\section{DISCUSSÃO}

O ambiente analisado traz aspectos positivos no que diz respeito ao seu contexto espacial. O primeiro a destacar é o fato de permitir o contato dos residentes com o preparo das refeições, já que o refeitório e a cozinha estão alinhados no corredor de acesso ao elevador e nesta passagem cotidiana olfato, audição e visão são estimulados. Segundo Bins Ely (2003), os estímulos sensoriais são o início do processo composto por atividades mentais que desencadeiam decisões e ações que se traduzem em comportamento. Neste caso, estimulam a vontade de comer contribuindo para a saúde dos pacientes e, ainda, para o desempenho das atividades dos funcionários que irão alimentá-los, já que é mais fácil alimentar alguém que deseja comer.

O segundo aspecto a destacar é a relação do ambiente com o exterior. A visualização da vegetação pelas janelas, o som dos pássaros, do vento e o ar fresco que circula na casa são fatores positivos destacados por todos. Pesquisas apontam que os ambientes naturais podem influenciar positivamente a vitalidade e a afetividade. Indivíduos que passam um tempo regularmente junto à natureza mostram mais vitalidade diária e sentimento de revitalização energética (Veitch, 2012). Assim influenciam na saúde mental das pessoas (Guitte, 2006). Este aspecto é relevante para a evolução do quadro de pacientes com doenças degenerativas ou depressão. Traz também benefícios para os funcionários que têm um cotidiano de trabalho com atividades intensas e desgastantes, como é o caso dos entrevistados.

O mobiliário aparece como aspecto negativo, tanto nas análises feitas pelas pesquisadoras quanto na opinião dos funcionários. Os itens analisados impõem dificuldades na realização das atividades necessárias para a alimentação dos residentes, tanto em relação ao dimensionamento quanto à forma, de acordo com os padrões estabelecidos na NBR 9050 


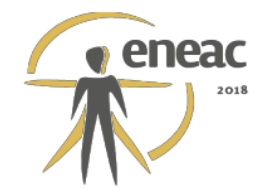

(2015) e conforme Panero \& Zelnik (2014).

Há também concordância no resultado da avaliação do refeitório no que diz respeito ao conforto ambiental, sendo que este é um aspecto muito positivo.

\section{RECOMENDAÇÕES E SUGESTÕES}

Realizadas as análises sobre o objeto de estudo, foram sugeridas melhorias gerais no ambiente, mantendo o tamanho do atual refeitório. Para adequar este espaço aos padrões estabelecidos na NBR 9050 (2015) e Panero \& Zelnik (2014) é necessário diminuir o número de cadeiras, que hoje são 16. A princípio não há problemas neste sentido, pois constatou-se que somente 8 dos 17 residentes utilizam o espaço durante as refeições. Como já citado, alguns fazem uso de sonda gástrica e não recebem o alimento ali. Outros possuem distúrbios comportamentais que infelizmente atrapalham o momento de refeição dos demais, por isso comem separadamente com auxílio de um técnico em enfermagem.

Pressupondo a manutenção das dimensões estruturais do refeitório, é possível acomodar 10 pessoas sentadas simultaneamente. Para tanto, uma solução possível é mudar a posição das portas, melhorando os fluxos no ambiente. Uma das portas seria destinada à entrada dos alimentos e a outra à retirada dos utensílios usados.

O serviço continuaria centralizado, porém neste caso livre do fluxo de abastecimento. As estantes antigas de madeira, com pouco uso, cederiam espaço para o buffet aquecido existente e para uma bancada em pedra clara, mais funcional e higiênica, com altura adequada. Nesta bancada estaria a comida fria, servida em temperatura ambiente, os utensílios e as bebidas. Uma parte também seria destinada à organização do material já utilizado durante a refeição, como louças e talheres.

As atuais mesas precisam ser substituídas por mesas maiores, com $110 \mathrm{~cm}$ de profundidade e pés encaixados nos quatro cantos, permitindo a aproximação mais confortável das cadeiras de rodas. É conveniente que as mesas propostas sejam retangulares para aproveitar melhor o espaço, pois segundo os padrões consultados, não é possível manter no refeitório quatro mesas quadradas de $110 \mathrm{~cm} \times 110 \mathrm{~cm}$, nem mesmo três, e garantir a circulação sugerida.

As cadeiras poderiam ser mais confortáveis para os idosos, com apoios para os braços, permitindo descanso dos membros durante a atividade, além de auxiliar no momento de levantar e sentar. É importante que a mobília seja confortável e funcional. Precisa ser leve, macia, com toque acolhedor e ter cores agradáveis. Modelos estofados, com estrutura em alumínio pintado ou madeiras leves, seriam adequados.

Para auxiliar os funcionários na atividade de alimentar os idosos seria adequado incluir duas cadeiras giratórias e com rodas no ambiente, facilitando a mobilidade na execução desta tarefa.

Um aspecto importante a ser melhorado seria instalar uma proteção solar, para que as cortinas possam ser mantidas abertas, mantendo a luz natural e a vista do jardim no café da tarde. Uma das soluções possíveis e imediatas seria a colocação de um toldo com tecido específico para proteção solar junto às janelas do ambiente. Poderíamos elencar outras soluções possíveis, tais como a execução de um pergolado de madeira com trepadeiras, ou o plantio de árvores que propiciem sombra em frente às janelas. 


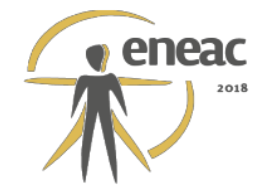

Figura 17 - Planta baixa da proposta com novo leiaute.

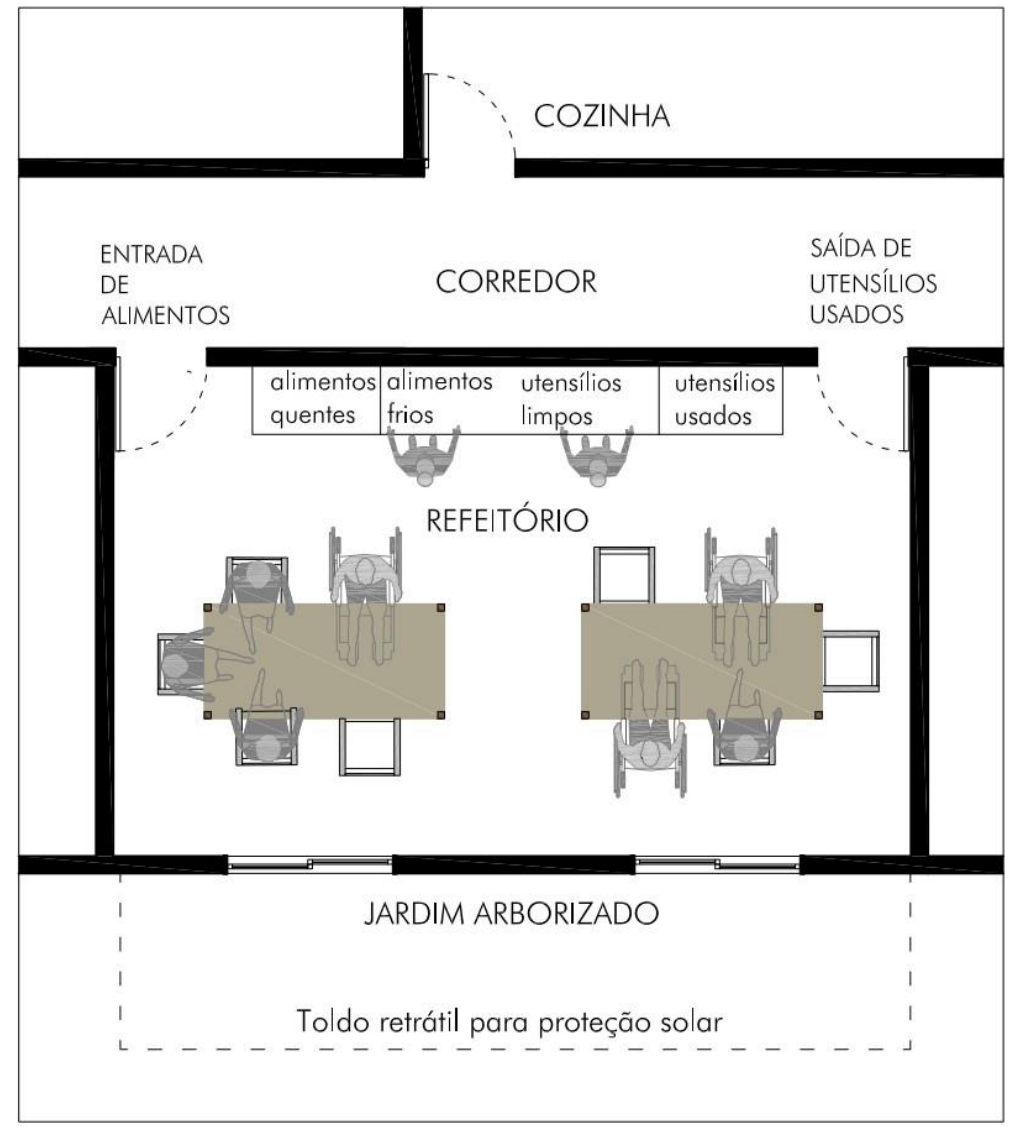

Fonte: Autores.

Figuras 18 e 10 - Perspectivas da proposta com novo leiaute.
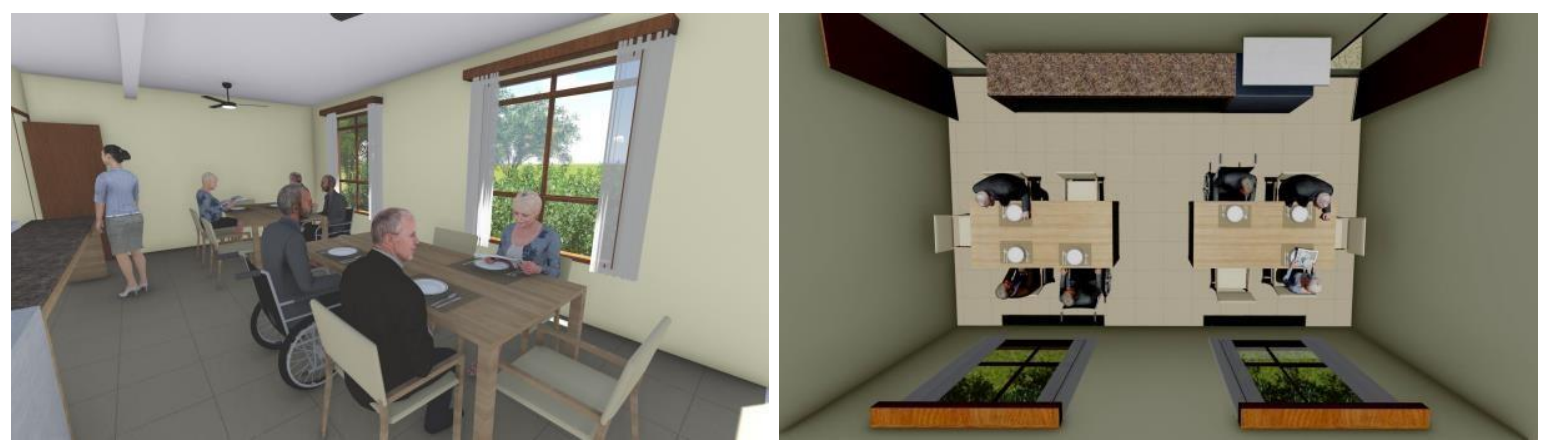

Fonte: Autores.

\section{CONSIDERAÇÕES FINAIS}

Em relação aos objetivos do estudo, concluímos que sob a ótica da ergonomia o ambiente tem vários aspectos a melhorar, principalmente no que diz respeito ao mobiliário.

Sobre os aspectos de humanização e elementos estruturadores do espaço identificamos que a comida ser preparada e servida de modo caseiro, com a conexão física entre circulação, cozinha e refeitório bem como o conforto ambiental, favorecem a alimentação dos idosos. Porém identificamos que os fatores estruturadores do espaço - como distribuição do leiaute e dimensionamento - dificultam a realização dessas atividades. Estes últimos tem origem na adaptação do ambiente para um uso que não foi planejado. 


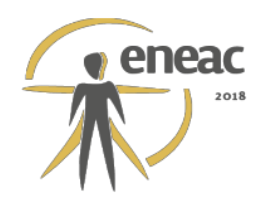

Verificamos que há traços do comportamento de apropriação dos usuários no ambiente como a territorialidade observada nos momentos de refeição, que foi confirmada pelas entrevistas com funcionários.

Sobre a estratégia metodológica adotada, concluímos que a união das observações com as entrevistas foi correta, pois permitiu obter informações oriundas do olhar das pesquisadoras com formação em arquitetura, e enriquecê-lo com a percepção dos funcionários diretamente envolvidos em aspectos que extrapolam os conhecimentos em arquitetura, como a saúde dos idosos. A abordagem multi-métodos foi importante principalmente neste caso, em que se analisou um ambiente voltado para pessoas que possuem doenças degenerativas e consequentemente limitações físicas e cognitivas.

\section{REFERÊNCIAS BIBLIOGRÁFICAS}

ASSOCIAÇÃO BRASILEIRA DE NORMAS TÉCNICAS. NBR 9050: Acessibilidade a edificações, mobiliário, espaços e equipamentos urbanos. $3^{\underline{a}}$ ed. Sp: Abnt, 2015. 148 p.

BINS ELY, V. H. M. Ergonomia + Arquitetura: buscando um melhor desempenho do ambiente físico. Anais do III Ergodesign - Congresso Internacional de Ergonomia e usabilidade de Interfaces Humano-Tecnologia: Produtos, Programas, Informação, Ambiente Construído. Rio de Janeiro: LEUI/PUC - Rio, 2003.

GARCIA DE MENEZES, M. F., LIMA TAVARES, E., MARTIM DOS SANTOS, D., LOUREIRO TARGUETA, C., DONIZETE PRADO, S. Alimentação saudável na experiência de idosos. Revista Brasileira de Geriatria e Gerontologia, 13 [en linea] 2010. ISSN 1809-9823

GUITE, H. F.; CLARK, C.; ACKRILL, G. The impact of the physical and urban environment on mental well-being. Public Health, v. 120, n. 12, p. 1117-1126, 2006. ISSN 00333506.

MINAYO, Maria Cecília de Souza. Pesquisa social: teoria, método e criatividade. Petrópolis: Vozes, 2011.

PANERO, Julius; ZELNIK, Martin. Dimensionamento humano para espaços interiores: um livro de consulta e referência para projetos. 1. ed. São Paulo: G. Gili, 2014. 320 p.

VEITCH, J. et al. Park Improvements and Park Activity A Natural Experiment. American Journal of Preventive Medicine, v. 42, n. 6, p. 616-619, Jun 2012. ISSN 0749-3797.

ULRICH, Roger S. Effects of healthcare Interior Design on Wellness: theory and recent scientific research. In: SYMPOSIUM ON HEALTHCARE DESIGN, 4, 1991, Boston. Innovations in healthcare design: selected presentations from the first five symposia on healthcare design. New York: Sara O. Marberry, 1995.

ZEISEL, John. Inquiry by Design: Environmental, Behavior, Neuroscience in Architecture, Interiors, Landscape and Planning. New York, 2006. 